Meta

Journal des traducteurs

Translators' Journal

\title{
Explicitation and Implicitation in Legal Translation - A Process Study of Trainee Translators
}

\section{Mette Hjort-Pedersen et Dorrit Faber}

Volume 55, numéro 2, juin 2010

URI : https://id.erudit.org/iderudit/044237ar

DOI : https://doi.org/10.7202/044237ar

Aller au sommaire du numéro

Éditeur(s)

Les Presses de l'Université de Montréal

ISSN

0026-0452 (imprimé)

1492-1421 (numérique)

Découvrir la revue

Citer cet article

Hjort-Pedersen, M. \& Faber, D. (2010). Explicitation and Implicitation in Legal Translation - A Process Study of Trainee Translators. Meta, 55(2), 237-250. https://doi.org/10.7202/044237ar

\section{Résumé de l'article}

Le présent article a pour objet d'examiner l'utilisation de l'explicitation et de l'implicitation dans le domaine de la traduction juridique. Sur le plan linguistique, les textes juridiques sont complexes et difficiles à comprendre pour les non-spécialistes. Du point de vue cognitif, on pourrait par conséquent s'attendre à ce que l'explicitation et l'implicitation apparaissent fréquemment dans les textes cibles juridiques, étant donné que les traducteurs ont tendance à laisser dans les textes cibles des traces de leur compréhension, fruit d'un travail ardu. D'un autre côté, les traductions dans le domaine juridique ont des conséquences juridiques dans le monde réel. Du point de vue juridique, on pourrait donc s'attendre à ce que l'explicitation et l'implicitation apparaissent assez rarement dans les textes juridiques traduits, vu l'effet, sur le plan juridique, que peuvent avoir l'ajout ou la suppression d'informations. Cependant, comment cette contradiction se traduit-elle dans les textes cibles produits par des traducteurs d'expertises variables ? Le présent article étudie le phénomène de l'explicitation et de l'implicitation dans les traductions réalisées par les étudiants en traduction. Notre hypothèse est que le manque de compétences suffisantes en matière de scénarios juridiques a plus de poids que les efforts mentaux des étudiants et que ceux-ci choisiront, pour plus de sûreté, de se restreindre aux explicitations et aux implicitations obligatoires.
Ce document est protégé par la loi sur le droit d'auteur. L'utilisation des services d'Érudit (y compris la reproduction) est assujettie à sa politique d'utilisation que vous pouvez consulter en ligne.

https://apropos.erudit.org/fr/usagers/politique-dutilisation/ 


\title{
Explicitation and Implicitation in Legal Translation - A Process Study of Trainee Translators
}

\author{
METTE HJORT-PEDERSEN \\ Copenhagen Business School, Frederiksberg, Denmark \\ mhp.isv@cbs.dk \\ DORRIT FABER \\ Copenhagen Business School, Frederiksberg, Denmark \\ df.isv@cbs.dk
}

\section{RÉSUMÉ}

Le présent article a pour objet d'examiner l'utilisation de l'explicitation et de l'implicitation dans le domaine de la traduction juridique. Sur le plan linguistique, les textes juridiques sont complexes et difficiles à comprendre pour les non-spécialistes. Du point de vue cognitif, on pourrait par conséquent s'attendre à ce que l'explicitation et l'implicitation apparaissent fréquemment dans les textes cibles juridiques, étant donné que les traducteurs ont tendance à laisser dans les textes cibles des traces de leur compréhension, fruit d'un travail ardu. D'un autre côté, les traductions dans le domaine juridique ont des conséquences juridiques dans le monde réel. Du point de vue juridique, on pourrait donc s'attendre à ce que l'explicitation et l'implicitation apparaissent assez rarement dans les textes juridiques traduits, vu l'effet, sur le plan juridique, que peuvent avoir l'ajout ou la suppression d'informations. Cependant, comment cette contradiction se traduit-elle dans les textes cibles produits par des traducteurs d'expertises variables? Le présent article étudie le phénomène de l'explicitation et de l'implicitation dans les traductions réalisées par les étudiants en traduction. Notre hypothèse est que le manque de compétences suffisantes en matière de scénarios juridiques a plus de poids que les efforts mentaux des étudiants et que ceux-ci choisiront, pour plus de sûreté, de se restreindre aux explicitations et aux implicitations obligatoires.

\begin{abstract}
This article explores the use of explicitation and implicitation in the context of legal translation. Legal texts are linguistically complex and difficult to understand for lay persons. From a cognitive point of view it may therefore be assumed that ex- and implicitations will be frequent phenomena in legal TTs, because translators will tend to leave traces of their hard-won understanding in the TT. On the other hand, legal translations have legal consequences in the real world. From a legal point of view it may therefore conversely be assumed that ex- and implicitations will be relatively rare phenomena in legal TTs because of the potential legal effect of adding or removing information. But how is this schism reflected in legal TTs performed by translators at different levels of expertise? This article examines phenomena of ex- and implicitations in trainee translator TTs. It is hypothesized that lack of sufficient knowledge of legal scenarios will override heavy mental processing efforts and that trainee translators will restrict themselves to choosing only obligatory ex- and implicitations as their safe bet.
\end{abstract}

\section{MOTS-CLÉS/KEYWORDS}

traduction juridique, explicitation, implicitation, processus cognitifs, protocoles de verbalisation

legal translation, explicitation, implicitation, cognitive processes, think-aloud protocols 


\section{Introduction}

This article examines aspects of explicitation and implicitation in legal translation on the basis of a think-aloud study involving trainee translators. Explicitation has been seen as an inherent feature of the process of translation, e.g., by Blum-Kulka (1986), who first put forward the so-called explicitation hypothesis "according to which translations are always longer than the originals, regardless of the languages, genres and registers concerned" (Klaudy 1998: 84). This hypothesis has been further explored by i.a. Klaudy and Károly (2005) and Pápai (2004). Explicitation has also been considered in the context of the strategies used by both non-professional and professional translators (Laviosa-Braithwaite 1996; Puurtinen 2003; Dimitrova 2005a and b). Implicitation seems to be a less frequent procedure (Klaudy and Károly 2005). Our key point of interest is to explore the explicitation hypothesis in the context of legal translation. Because of the specific functions of legal texts, legal translations made by trainee translators may be assumed not to comply with the explicitation hypothesis due to the risks involved.

\section{Background}

In legal translation a number of factors play a role. Compared with many other text types, legal texts such as Acts of Parliament, judgments, and contracts are special because they do not merely describe or inform the reader about some state of affairs in the world, but in terms of speech act theory they are also partly performative, which means that they create new states of affairs in the world (Searle 1989). A contract, for instance, will create rights and obligations resting on the parties to the contract, and a judgment may impose on an individual a duty to perform certain actions. In other words, legal texts have consequences. Another characteristic of legal texts is that they are linguistically quite complex and difficult to understand for nonexperts because of their frequent use of passive and nominal constructions, script roles and legal terminology. All of these linguistic features mean that in order to arrive at a successful construction of the text scenario the reader, and especially the lay reader, has to perform extensive inferencing. This type of inferencing may be seen as a kind of mental explicitation, which involves the cognitive identification and explicitation of who the actants are, how they interact, as well as the time, place and cause of the events described by a legal text.

On the basis of the above factors, two general assumptions about explicitation and implicitation can therefore reasonably be made with regard to translation of legal texts. From a legal point of view, adding or subtracting information in legal translation is a high-risk procedure because of the potential change of legal meaning and/or effect of the target text, and therefore it is reasonable to assume that explicitation and implicitation will be a relatively rare phenomenon in legal translation. Renato Correia, a translator working in the EU, decribes the crux of the problem as follows: "Translating means choosing; but how does one make the right choice when the best linguistic solutions might be undesirable, because they could have unintended political or legislative consequences?" (Correia 2003: 42).

Conversely, from a cognitive point of view the assumption may be quite the opposite. Legal texts describe legal scenarios that are on the whole unfamiliar to lay 
readers, and the language used to describe these scenarios is linguistically relatively complex. On this basis, it might therefore be assumed that the effort involved in the necessary mental processing will leave traces in the target text in the form of linguistic explicitation and/or implicitation. This assumption finds support in Pym (2005), who discusses the relationship between discursive complexity and frequency of explicitation in translation. Referring to Whittaker (2004), whose work showed increased instances of explicitation in passages marked by greater discourse complexity, Pym hypothesizes that "the harder the source text, the harder the translator works, and the more likely they are to make their renditions explicit” (Pym 2005: 8-9).

Steiner (2001) also discusses the efforts involved in the translator's understanding of the source text as a source of explicitation. Working within the theory of Halliday's systemic functional grammar Steiner sees the translator's understanding of the source text as a process of de-metaphorisation of what is called grammatical metaphors. This de-metaphorisation involves

relating meaningful (grammatical) units to some of their less metaphorical variants, thus making many types of meaning which are implicit in the original explicit with the help of co-textual and contextual knowledge. At some point in that chain of de-metaphorization, then, re-wording in the target language begins, and although good translators will approximate a full semantic paraphrase [...], they will often not go all the way back up the steps of grammatical metaphorization, either for contrastivetypological reasons, or simply because of internal fatigue (Steiner 2001: 11).

The result will thus be a target text with a higher degree of explicitness.

To our knowledge, no studies have been undertaken specifically of the relationship between discourse complexity and instances of implicitation. Laviosa-Braithwaite (1996: 155) refers to earlier studies by Vanderauwera (1985) that showed "evidence of syntactic simplification in connection with difficult and complex syntax as well as omissions or reductions of overlong circumlocutions and irrelevant details."

But what is the situation in the real world of legal translation? How is this schism between legal and cognitive factors actually reflected in translations performed by translators representing different levels of legal and translational expertise (professional translators and trainee translators)? Or, in other words, what is the correlation between any mental explicitation of the complexities of a legal ST and linguistic explicitation or implicitation in legal translations performed by the two groups, respectively. This question is interesting from a didactic/pedagogical point of view because what professional translators do and do not do when translating legal text in a sense represents the norm that trainee translators are working towards in what they do and do not do.

This study looks specifically at trainee translators, who represent the lowest level on the scale of expertise. Trainee translators can be characterised as having some knowledge of translation processes, but limited knowledge of the legal domain as opposed to the professional legal translator operating at the other end of the scale of expertise.

For the group of trainee translators, an extra and more specific assumption to supplement the more general assumptions may therefore be made: The complexity of legal texts is so high and the trainees' level of legal expertise is so limited that any mental explicitation of actants, places, times, etc. in the process of understanding a legal text will only be reflected in their translation to a very limited extent. Thus, we 
expect that a fairly literal translation will be chosen by the trainees as the safest choice, so that only instances of obligatory implicitations and explicitations, i.e., implicitations and explicitations dictated by differences in language systems, will be found.

To explore this assumption the following research questions were formulated: Do trainee translators engage in mental explicitation of the actants, their interaction, the time, place and cause of events in their cognitive processing of the features that are considered to add complexity to legal texts? And if they do, what happens to this mental explicitation in the target text (TT), is it transferred to or omitted in the TT, or is it followed by any instances of implicitation in the TT? Conversely, if they do not engage in source text (ST) mental explicitation, does this mean that there is a corresponding absence of linguistic explicitation in the TT, can linguistic explicitation still be found in the TT, or is there any implicitation in the TT of source language (SL) textual units.

Furthermore, if our assumption is rebutted and the trainees do in fact engage in linguistic explicitation or implicitation in their legal translation, what types of explicitation and implicitation do they then opt for? And what may be the reasons behind the trainees' choice of linguistic explicitation or implicitation?

\section{Data and methodology}

The data we base our discussions on are think-aloud protocols and legal translations produced by Danish M.A. students of English for Specific Purposes working in pairs. All of these trainees had received prior translation training both at the B.A. and the M.A. levels, and they were native speakers of Danish.

We designed a project and chose concurrent think-aloud with video-recording of the eight trainees' discussions. The actual translation process was logged in the software program Translog (Jakobsen 1999). It may be argued that eight is a fairly limited number of informants. However, the number is connected with the thinkaloud method and the considerable amount of data resulting from such think-aloud protocols (TAPs) and is in line with the tradition in process studies, see e.g., Dimitrova (2005b).

It was very important for this particular study that the trainees actually verbalised their thoughts about the meaning of the text to be translated, which we knew would be difficult for them to understand, although it represented a genre they were familiar with. We therefore chose to let them work in pairs because they would then have to account to each other for their individual understanding and suggested translation choices (Haastrup 1991; House 2000; Jääskeläinen 2000).

\section{The source text with focus points}

Our source text was an extract of a Danish law report that contained a quotation from the judgment reported. It consisted of a total of 103 words, and the trainees were given 75 minutes, which they all used fully. They were also provided with background information in the form of a larger part of the law report, which contained the essential information on the proceedings up to the stage described in the text to be translated, but like the source text proper, the background text was also linguistically fairly 
condensed. Dictionaries, both general and legal were provided, and the trainees had access to the Internet. In addition, the trainees were given a simulated translation brief specifying the commissioner of the translation and the target group, but no other directions were given on how to work with the translation assignment.

Even though the ST was Danish, it represented in a sense a foreign language to the trainees because of their limited source language competence in this particular field of Langage for Specific Purposes (LSP), which means that they would undoubtedly have to work hard to understand the ST and translate it into their TT.

The points that we chose to focus on in the reader's overall ongoing inferencing process reflect characteristics of legal style and can be exemplified by a number of questions that could be asked by the reader in relation to nominalisations, passives, culture-bound terms and elliptical phrases, etc. in order to accomplish a successful scene creation. It should be mentioned, however, that we did not in fact ask the trainees explicitly to think along these lines.

An alternative to zooming in on such focus points would be to analyse all verbalisations of mental explicitation performed by the trainees. However, with the focus points, we shall be able to correlate the findings of this study with findings of future studies we intend to conduct involving professional translators.

The section of our source text that we intend to discuss here (69 words) is represented below:

\section{Source text}

[...] retsplejelovens $\$ 248$ findes dog ikke at udelukke, at byretten som sket har tilladt fremsættelse af afvisningspåstand grundet på indsigelse mod værnetinget. Afgørelsen findes heller ikke uforenelig med EF-domskonventionens artikel 18, idet sagens forberedelse for byretten på tidspunktet for kærendes processkrift af 15. april 1999 ikke var fremskreden. Det tiltrædes derfor, at byretten har tilladt kærende i henhold til processkrift af 15. april 1999 at fremsætte påstand om afvisning.

To illustrate the processing task involved in understanding the translation task, i.e., filling in the slots connected with our focus points, we have drawn on the relevance theory concepts reference assignment (RA) and enrichment (EN), and applied them to our below translation of the ST. For our purposes, reference assignment involves accessing (that is retrieving) a mental representation which uniquely identifies the intended referent (Blakemore 1992: 68). Enrichment represents the process of filling in missing information in a linguistically encoded semantic representation (Blakemore 1992: 61). The text section that we consider here did not contain any problematic cases of lexical polysemy, which is why the category of disambiguation was not included in our analysis.

To facilitate comparison with the ST, this particular translation retains the structure of the original and conveys the meaning on an almost word to word basis.

Our (very) close translation

The Administration of Justice Act (which? RA) section 248 is found (by whom? EN) however not to exclude that the City Court (which? RA) as was the case (in relation to what/when - EN) has allowed the submission (by whom? EN) of a motion for dismissal based on objection (by whom? - EN) to venue. The decision (which? - RA) is also found not to conflict with the European Judgments Convention article 18 as 
the preparation (by whom? - EN) of the case before the City Court at the time of the appellant's statement of case (who/which? - RA) of 15 April 1999 was not advanced. It is therefore accepted (by whom? - EN) that the City Court has allowed the Appellant in accordance with the statement of case dated 15 April 1999 to make a claim for dismissal.

Where the same text unit appeared several times in the text, we assumed that these units were processed in the same way, and therefore only included the unit once as a focus point.

\section{Inferencing and translating}

There is no doubt that the trainees struggled a great deal both to understand and translate the source text. This is evidenced for instance by the numerous expressions of uncertainty in the TAPs, such as "this is not easy," "I'm not sure," "this is annoying," "maybe," etc. (see Hjort-Pedersen and Faber [2009]). The trainees also had lengthy discussions about target language legal terminology that did not involve mental explicitation of who, when, where, etc. However, such discussions were not considered to be instances of mental explicitation. They consulted dictionaries and the Internet on numerous occasions to support both the understanding and the translation process. The entire process of understanding and translating a mere 69 words took the four pairs 56.06, 49.09, 47.06, and 34.55 minutes, respectively. It should be noted that the cognitive ST processing cannot always be kept separate from the translation process, as a dictionary consultation may give rise to further processing. Nor does the logging of activities through Translog help separate the time spent on mental explicitation and translation, since in connection with pair think-aloud actual logging is only effected once the trainees have completed their discussion of meaning and agreed on their translation proposal. However, Translog allowed us to record the total amount of time spent on each focus point, and was therefore an important indicator of the mental effort involved in the overall process of understanding and translating.

\subsection{Mental explicitation}

The mental explicitation results are summarised in Table 1 below. The columns containing plus signs represent the processes of the four pairs, referred to as $M \& M, T \& A$, $A \& M$, and K\&M. The focus points, i.e., the linguistic units that reflect complexities of legal style, involved 4 instances that required reference assignment, and 6 instances to be enriched. It was found that the four pairs did indeed engage in mental explicitation in connection with these focus points, namely in 8 out of 16 possible reference assignment processes (50\%), and in 19 out of 24 possible enrichment processes (79.16\%). 
TABLE 1

Mental explicitation

\begin{tabular}{|l|l|c|c|c|c|c|}
\hline \multicolumn{2}{|c|}{ Linguistic unit } & $\begin{array}{c}\text { Mental } \\
\text { explicitation }\end{array}$ & M\&M & T\&A & A\&M & K\&M \\
\hline RA & Administration of Justice Act & 0 & & & & \\
\hline EN & is found & 3 & + & + & + & \\
\hline RA & The City Court & 3 & + & & + & + \\
\hline EN & as was the case & 3 & & + & + & + \\
\hline EN & $\begin{array}{l}\text { submission (of motion of } \\
\text { dism..) }\end{array}$ & 3 & + & + & + & \\
\hline EN & objection (to venue) & 2 & + & & & + \\
\hline RA & The decision & 2 & + & + & & \\
\hline EN & preparation (of the case) & 4 & + & + & + & + \\
\hline RA & the app.'s statement of case & 3 & + & + & + & \\
\hline EN & is accepted & 4 & + & + & + & + \\
\hline
\end{tabular}

The inferencing processes of the four pairs with respect to our focus points shared a number of features:

1. Reference assignment is verbalised a good deal in most cases by the informants. A particular kind of mental explicitation, i.e., that employed in connection with the identity of source text culture-bound terms, could be classified as borderline cases. Here, the reference assignment is made by the informants on the part of the TT reader rather than as part of the understanding process. In these cases, there is either no verbalisation or limited verbalisation.

2. Where a lexical unit required enrichment, the pairs discussed who or what may be connected with the acts described by the passives and the verbal nouns. As for the individual linguistic units requiring enrichment, the amount of mental explicitation may be viewed on a continuum, with passive constructions prompting the highest degree of observations by the informants with a score of 7 out of 8 possible (87.5\%). Nominalisations follow with 9 out of 12 possible (75\%). The elliptical phrase som sket (as was the case) resulted in mental explicitation by 3 out of 4 pairs (75\%).

\subsection{Target text with linguistic explicitations and implicitations}

We now go on to look at the trainees' TTs to see if their mental explicitation processes are reflected here, and if so, how. First, however, we need to specify the types of explicitation and implicitation that we considered relevant for our purposes. On the basis of Perego (2003: 73) and Klaudy and Károly (2005: 15), they are defined as follows. Explicitation is of two types: addition and specification.

1) Addition (A) is quantitative in nature, and involves the inclusion in the TT of extra lexical elements that either add or repeat meaningful elements;

2) Specification (S) is qualitative, i.e., it adds meaning(s) by using lexical elements that are semantically more informative.

Similarly, we consider implicitation to be of two kinds: 
1) Reduction (R), which involves leaving out meaningful ST lexical elements in the TT;

2) Generalisation $(G)$, which involves using TL lexical elements that are semantically less specific than the ST lexical elements.

Table 2 shows the overall correlation between the four pairs' mental explicitation and linguistic explicitation and/or implicitation in the TT as well as the types of linguistic explicitation or implicitation undertaken.

TABLE 2

Mental explicitation and linguistic explicitation/implicitation

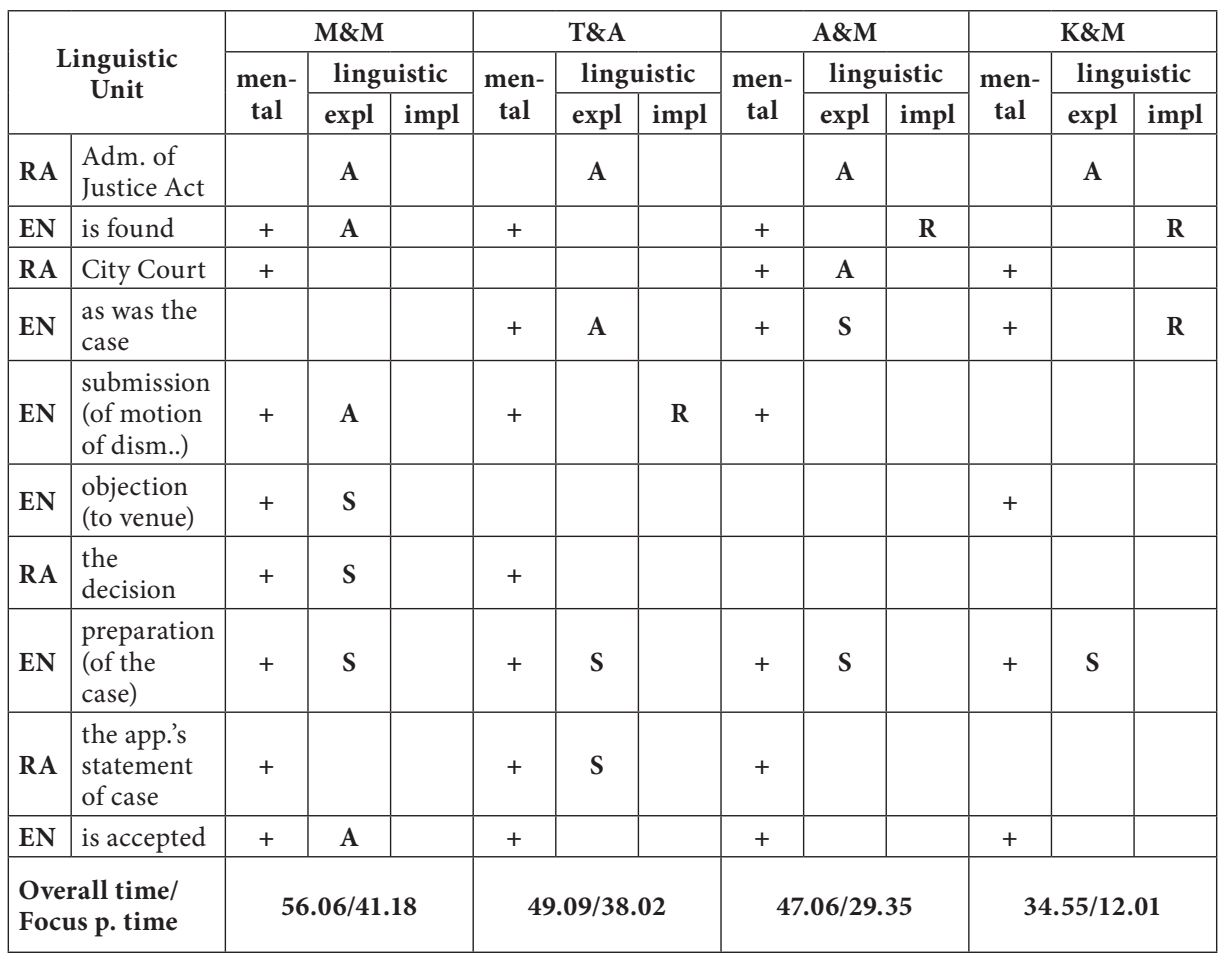

The total number of mental explicitations verbalised by the informants in relation to the focus points is 27 . Out of these mental explicitations, 14 (51.85\%) are mirrored by linguistic explicitations in the TTs. In 11 cases (40.74\%), the mental explicitation is not reflected in the TTs. Only 2 instances of mental representation (7.40\%) are followed by linguistic implicitation in the TT.

Conversely, there are 5 cases of linguistic explicitation or implicitation that are not preceded by any mental explicitation.

\section{The analyses}

As mentioned, it was assumed that the trainees would prefer a near-literal translation with only obligatory linguistic explicitation or implicitation because that would be the safest bet, but surprisingly, as Table 2 shows, this was not the case. 
If we look at the details in connection with the enrichment processes, we find that there are differences in the way the trainees handle nominalisations and passives in their TTs. Where the pairs opt for a non-literal translation of the passives, they choose either addition or reduction. With nominalisations, on the other hand, they seem to prefer a specification strategy and do not add extra linguistic material, for instance in the form of information about who performs the act described by the verbal noun. As for the elliptical phrase som sket (as was the case), the picture is less clear in that both addition, specification and reduction are opted for.

With regard to reference assignment, the most striking feature of linguistic explicitation is addition, which is used in connection with culture-bound terms. Four out of five instances of addition, however, are not results of prior mental explicitation but an automatic process. The fifth instance, though, reflects the mental explicitation performed in the understanding process.

Specification is also used, but to a lesser extent, and only in cases where the pairs in their discussions have succeeded in sorting out tokens of a particular type of legal entity. Interestingly, generalisation as a strategy was never chosen.

Even though there is no direct linguistic evidence in terms of what the trainees say in the TAPs that explains the above difference in the informants' approach to nominalizations and passives, the protocols show that it may be connected with what the trainees do, namely their use of bilingual legal dictionaries. If it is possible to look up (what the trainees think are) equivalent nouns in the dictionary, there is no incentive for them to add anything. With the passives, on the other hand, what they find in the dictionary is of course the infinitive form, which they then have to transform by producing either an active or a passive sentence. The TT result is either addition or a literal translation. So, although there is preceding mental explicitation, it does not seem to be the only factor that triggers the trainees' explicitation strategy for the TT. To illustrate this let us consider the verbalisations in the TAPs in connection with some of the focus points. It should be noted that the TAP dialogue was in Danish and what follows is our translation. We do not discuss the quality of the translations in detail, as quality assessment would be a study in its own right.

\subsection{Enrichment of passives}

We start out with the passive findes (is found), which is dealt with by M\&M in the following way. They begin by looking up an entry for the Danish verb finde, which gives them find. They discuss who is doing the finding and they go on to incorporate their mental explicitation in the translation with an addition.

- we could rephrase it somewhat so that it is easier to translate - right

- yes - so for instance - that the court does not find that s 248 prevents the City Court -

They agree that this is a good way to translate the beginning of the sentence:

- should we put in the court first - that is - the Danish High Court does not find - is it okay to use find (dictionary consulted) that section - of the Administration of Justice Act - that makes it easier - yes

The target text result is then addition of both agent and location of that agent: The Danish High Court does not find. 
The strategy used by this pair could be connected with their text flow preferences, i.e., their perceptions of target language norms ("that makes it easier - yes") lead them to favour an active or a passive construction in their TT to promote the flow of the text. There are however no direct discussions about TL preferences, text conventions, etc. Once they have established who the actant is, the rest seems unproblematic, which means that their solutions, addition or literal translation, seem to be an integrated part of their repertoire.

A similar operation but with a somewhat different result is seen with A\&M, who choose a reduction strategy. They opt for the active tense, but end up choosing the wrong subject.

- I am not even sure I understand the Danish text -

- Okay - if one does not find -

- no - if something in the Danish Administration of Justice act does not find -

- maybe we can just start out by saying does not exclude -

- well it means that the Administration of Justice Act does not exclude

In this case the target text result is a reduction because the passive verb findes (is found) is omitted in the translation: [...] the Danish Administration of Justice Act does not exclude that ...

Judging from the TAP, the strategy used here most likely results from the informants trying to gloss over a lack of understanding. It is obvious that they fail to recognise the performative status of the utterance which in their translation turns out as descriptive.

T\&A identify the actant behind the verbal phrase, but neither add nor leave out any lexical elements:

- I don't even know what they mean - oh I think it means that the Administration of Justice Act does not exclude - well I think that we need to include findes because it is what the court thinks...

In this case the target text result is a literal translation: The Danish Administration of Justice Act is found...

With the second passive tiltrædes (is accepted), three pairs choose a literal translation, and only M\&M continue to choose addition (of an actant). This strategy may be idiosyncratic and simply an expression of text-flow preferences.

\subsection{Enrichment of nominalisations}

To illustrate the difference with respect to enrichment of passives and nominalisations, we next look at the most clear-cut case of non-literal translation of nominalisations, i.e., the translation of (sagens) forberedelse (the preparation [of the case]). All pairs perform mental explicitation, and in their TT they choose a specification, but without adding any agent in connection with the verbal act. This strategy seems to be prompted by their dictionary consultations: they simply look up the term forberedelse (preparation) and find the entry of pre-trial stage with a dictionary explanation:

(Looking in the dictionary):

- okay listen to this - preparation as specific part of the court proceedings - pre-trial stage - yes that might be it - as the pre-trial stage that sounds good - we'll take that one 
The target text result is thus a specification of the more general Danish term forberedelse (preparation), as the pre-trial stage of the case.

\subsection{Enrichment of elliptical phrase}

The elliptical phrase som sket (as was the case) resembles the passive-form focus points in that the trainees cannot look it up in the dictionary. On the basis of their mental explicitation of the unit, A\&M handle this problem by choosing a specifying time adverbial:

- It means that it has happened before, right?

so that their target text result is specification: previously.

However, with K\&M the same process of mental explicitation of som sket (as is the case) leads to implicitation. They leave the phrase in Danish in their first draft. Then in the revision phase they explicitly choose a reduction strategy by deciding to omit the elliptical phrase altogether:

- We still haven't done anything about som sket - it is really annoying this som sket -

- but it is something which has happened -

- I was thinking we wrote has allowed so we said it didn't we -

- yes sort of - they did it - it has happened

This may again be a case of glossing over lack of understanding, or the trainees understand the SL phrase as an element that can be inferred from the TT perfect tense, so that their reason for the implicitation in the TT may be connected with what we have referred to as text-flow preferences.

\subsection{Reference assignment in connection with culture-bound elements}

Finally, we turn to examples of reference assignment elements where the mental explicitation percentage is low. With Retsplejeloven (the Administration of Justice $A c t$ ), we see a rare case of total agreement amongst the pairs as to processing and behavioural pattern. For none of the four pairs is there any evidence in the TAPs of mental explicitation, and yet they all choose linguistic explicitation in the form of the addition of the localising generic adjective Danish: The Danish Administration of Justice Act...

This choice is made automatically and according to the TAPs it is connected with pragmatic or cultural considerations. With byretten (the City Court), the TAPs show that three of the pairs verbalise their thoughts about the localisation of the court, e.g., A\&M:

- by the way with regard to the City Court - we are in Copenhagen right ...

$\mathrm{A} \& \mathrm{M}$ choose to retain their reflection in the target text by way of an addition: The Copenhagen City Court. The rest of the pairs decide that any addition is unnecessary, e.g.,

- do we need to insert Danish - we've said that once so we know where we are - right

The target text results show a (more or less) literal strategy without the addition of a generic expression: The District Court.../City Court... 
With regard to the assignment of reference to afgørelsen (the decision), two pairs ( $M \& M$ and $T \& A)$ discuss which decision the text refers to:

- This is the City Court's decision - not the High Court's - right (T\&A)

- It refers back to what was appealed from the City Court (M\&M)

This mental explicitation is not transferred to the TT of T\&A, they opt for a literal translation: the decision. With M\&M, however, the result of the mental explicitation is different. They choose to translate afgørelse as the order, which represents a specification that this is a particular decision relating to an interlocutory appeal from the City Court and not a final judgment. This choice is dictionary based, once they realise the nature and origin of the decision they feel confident enough to choose between the more general and the more specific term presented to them by their translation dictionary. The other two pairs do not engage in mental explicitation and choose a literal translation.

The fourth focus point requiring reference assignment kærendes processkrift (the appellant's statement of case) prompts mental explicitation with three of the pairs, who discuss whether kærende (the appellant) is the claimant or the defendant. They do not, however, use their mental explicitation to specify in their translation who the appellant is, they find a direct equivalent, the appellant, and opt for that without further discussion. One of the pairs (T\&A) discusses what the referent of processkrift is:

- What if processkrift covers all of the documents used in a lawsuit

- Yes, this is how it is used here (surfing on the Internet).

This mental explicitation is subsequently reflected in their translation in that they choose to specify the exact nature of this document: the appellant's notice of appeal (although this is in fact not the correct representation of the source text meaning).

\subsection{Summing up the analyses}

The different types of reflections as evidenced by the TAPs and the different TT results seem to be connected with a number of factors. Pragmatic or cultural considerations generally have to do with the need to supplement the target reader's general assumptions about the legal culture in which the text is rooted. Where this kind of explicitation occurs with our trainees, it is automatic, i.e., it would classify as norm-governed in Dimitrova's typology (2005b: 236), belonging to the kind of explicitation which is undertaken as part of a non-problematic processing. Examples are found in connection with the adding of a generic element (Danish/Copenhagen) to a proper name (Administration of Justice Act/City Court).

Text-flow preferences are connected with paraphrasing of both ST and TT textual structures. In this study, this is reflected e.g., in some of the trainees' preference for active rather than passive voice, they feel that it is easier to construct a TL sentence if they specify/add the actant or actants involved. So from this perspective, this explicitation is strategic and is used to solve a problem. On the other hand, the operation is carried out more or less instantly, which seems to indicate a norm-governed strategy.

The trainees did not verbalise any thoughts about genre conventions that might have been found with a different pair of informants with a higher level of expertise. 
Dictionary or Internet inspiration of course also reflects problem-solving processes, and is therefore strategic. The trainees are very dependent on the solutions offered in the specialised legal dictionaries and often such dictionary entries will prompt them to specify lexical meaning or add lexical elements. Lack of understanding turns out to be a trigger of implicitation in our study. Again, this is a strategic procedure simply to get on with the translation.

\section{Conclusion and perspectives}

As we had expected, our analyses have shown that the pairs spent quite a lot of time processing and translating the focus points. What surprised us was that in more cases than we had expected they were willing to run the risk of linguistic explicitation or implicitation in spite of the legal consequences and risks involved. Thus, they did not restrict themselves to obligatory linguistic explicitations and implicitations as the safest choice. However, it is of course possible that their choices in this study may differ from what they would do in a real-life commission.

The types of linguistic explicitation and implicitation chosen by our trainees were addition or specification and reduction. Addition is used where they implement their mental explicitation in the TT - as hypothesized by Pym (2005). Addition is also found without any preceding mental explicitation, in which case the trainees must have internalised some kind of norm of their own - what Dimitrova (2005b: 236) refers to as norm-governed explicitation. Specification, on the other hand, reflects extensive dictionary consultation. With respect to implicitation, we have found only reduction, but no examples of generalisation. This could be a sign that the trainees have insufficient knowledge of the legal systems involved, or that they have not incorporated generalisation as a strategy in their translation repertoire.

Another interesting result yielded by this study is that the trainees do not seem to be (consciously) aware that what they are doing when they choose linguistic explicitation or implicitation is to add or leave out information. At least, there are no discussions in the TAPs that indicate such awareness. Nor is there any evidence in the TAPs of the trainees discussing whether linguistic explicitation or implicitations would conflict with any text type conventions or relevance criteria in the expert-toexpert communication in which they serve as mediator.

Because of the limited number of informants in this particular study, the results are of course indicative rather than conclusive, but they will be supplemented with other experiments involving other types of informants. Thus, the next logical step will be to look at translations produced by professional translators. What we want to examine is whether a different correlation between the mental explicitation and linguistic explicitation and implicitation can be found. Also, we want to examine the extent of any overlap or mismatch between the underlying causes of trainees' and professionals' linguistic explicitation and implicitation strategies. In this way, we hope to get a more detailed picture of the processes involved in moving up the scale of expertise in legal translation.

\section{ACKNOWLEDGEMENTS}

We wish to thank Inger Mees and Louise Denver for making a number of helpful suggestions and Joan Tournay for her help in translating the abstract into French. 


\section{REFERENCES}

Blakemore, Diane (1992): Understanding Utterances. An Introduction to Pragmatics. Cambridge: Blackwell.

Blum-KulKa, Shoshana (1986): Shifts of Cohesion and Coherence in translation. In: Juliane House and Shoshana Blum-KulKa, eds. Interlingual and intercultural communication. Tübingen: Gunter Narr Verlag, 17-35.

Correia, Renato (2003): Translation of EU Legal Texts. In: Arturo Tosi, ed. Crossing Barriers and Bridging Cultures. The Challenges of Multilingual Translation for the European Union. Clevedon: Multilingual Matters, 38-44.

Dimitrova, Birgitta Englund (2005a): Combining Product and Process Analysis: Explicitation as a Case in Point. Bulletin Suisse de Linguistique Appliquée. 81:25-39.

Dimitrova, Birgitta Englund (2005b): Expertise and Explicitation in the Translation Process. Amsterdam: John Benjamins.

HaAstrup, Kirsten (1991): Lexical Inferencing Procedures. Tübingen: Gunter Narr Verlag.

HJort-Pedersen, Mette and Faber, Dorrit (2009): Uncertainty in the Cognitive Processing of a Legal Scenario: A Process Study of Student Translators. Hermes - Journal of Language and Communication Studies. 42:189-209.

House, Juliane (2000): Consciousness and the strategic use of aids. In: Sonja TIRKKONEN-CONDIT and Riitta JäÄskeläInen, eds. Tapping and Mapping the Processes of Translation and Interpreting. Outlooks on Empirical Research. Amsterdam: John Benjamins, 149-162.

JÄÄSKELÄINEN, Riitta (2000): Focus on methodology in think-aloud studies on translating. In: Sonja Tirkkonen-Condit and Riitta JäÄskeläinen, eds. Tapping and Mapping the Processes of Translation and Interpreting. Outlooks on Empirical Research. Amsterdam: John Benjamins, 71-82.

Jakoвsen, Arnt Lykke (1999): Logging Target Text Production with Translog. In: Gyde Hansen, ed. Probing the Process in Translation. Copenhagen: Samfundslitteratur, 9-20.

Klaudy, Kinga (1998): Explicitation. In: Mona Baker and Kirsten Malmkjaer, eds. Routledge Encyclopedia of Translation Studies. London: Routledge, 80-85.

KLAUdy, Kinga and KÁROLY, Krisztina (2005): Implicitation in translation: empirical evidence for operational asymmetry in translation. Across Languages and Cultures. 6(1):3-28.

LAVIOSA-BRAithWAite, Sara (1996): Comparable corpora: towards a corpus linguistic methodology for the empirical study of translation. In: Marcel TheLEN and Barabara LEWANDowsKATomaszczy к, eds. Translation and Meaning, Part 3. Maastricht: Euroterm, 153-163.

PÁpAi, Vilma (2004): Explicitation: A universal of translated text? In: Anna Mauranen, ed. Translation Universals. Do They Exist? Amsterdam: John Benjamins, 143-164.

Perego, Elisa (2003): Evidence of explicitation in subtitling: Towards a Categorisation. Across Languages and Cultures. 4(1):63-88.

Puurtinen, Tiina (2003): Explicitating and implicitating source text ideology. Across Languages and Cultures. 4(1):53-62.

PyM, Anthony (2005): Explaining Explicitation, version 2.2. Visited 19 March 2010, <http://www. tinet.cat/ apym/on-line/translation/explicitation_web.pdf $>$.

SEARLE, John R. (1989): How performatives Work. Linguistics and Philosophy. 12(5):535-558.

STEINER, Erich (2001): Translations English - German: investigating the relative importance of systemic contrasts and of the text-type "translation." Visited 19 March 2010, <http://www. hf.uio.no/forskningsprosjekter/sprik/docs/pdf/Steiner-neu.pdf>.

Vanderauwera, Ria (1985): Dutch Novels Translated into English: The transformation of a "minority" literature. Amsterdam: Rodopi.

Whittaker, Sunniva (2004): Étude contrastive des syntagmes nominaux démonstratifs dans des textes traduits du français en norvégien et des textes sources norvégiens: stratégie de traduction ou translationese? Forum 2(2):221-240. 